\title{
DIÁLOGOS ARTÍSTICOS EN EL SIGLO X. LA IMAGEN ARQUITECTÓNICA DE SAN MIGUEL DE CELANOVA ${ }^{1}$
}

\author{
ARTISTIC DIALOGS IN THE 10TH CENTURY. \\ THE ARCHITECTURAL IMAGE OF SAN MIGUEL \\ DE CELANOVA
}

\author{
$M^{a}$ DOLORES BARRAL RIVADULLA \\ Universidade de Santiago de Compostela
}

\begin{abstract}
Resumo
La arquitectura de San Miguel de Celanova debe de ser valorada a través de la singularidad del momento histórico-artístico en el que se genera. Este trabajo propone una lectura de su imagen arquitectónica lejos de formalismos y dentro de una línea argumental que presenta al edificio como reflejo de un conjunto de influencias estéticas que denota un proyecto homogéneo y una clara intención estilística.
\end{abstract}

\section{Palabras claves}

Arquitectura - Alta Edad Media- Siglo XSan Rosendo

\begin{abstract}
The architecture of San Miguel de Celanova must be valued from the singularity of the context of the 10th. This work proposes a reading of his architectural image far from formalisms and studies the building as a set of aesthetic influences that there denotes a homogeneous project and a clear stylistic intention.
\end{abstract}

\section{Keywords}

Architecture- Middle Ages- 10th CenturySan Rosendo

\footnotetext{
${ }^{1}$ Entregado el 20.03.2009
} 


\section{La singularidad del siglo $X$}

La arquitectura de San Miguel de Celanova debe de ser valorada a través de la singularidad del momento histórico en el que se genera. Un punto de encuentro y de renovación, un momento particular en el que la península converge hacia nuevas formas, políticas, intelectuales o religiosas... a estas coordenadas se une la particular idiosincrasia de la Galicia del siglo X.

A nivel político a comienzos de esta centuria Galicia no es más que un área integrada en el reino astur. Tras la destitución de Alfonso III quedará convertida en un reino independiente y a comienzos del siglo XI será integrada en el reino de castellano-leonés. En su evolución intrínseca se observa una mayor pujanza de la nobleza, que llega a ser clave en el gobierno del territorio, un importante "renacimiento" monástico y, como no, durante este siglo quedará patente la vitalidad del culto al apóstol Santiago, a cuya basílica comienzan a llegar importantes peregrinos.

En este particular contexto surge y destaca con entidad propia la figura de San Rosendo (907-977). Hijo de Gutierre Menéndez e Ilduara Eriz nació en el seno de uno de los linajes más importantes de la Galicia altomedieval. Recibirá una formación tradicional ocupando importantes cargos dentro de su carrera eclesiástica como las sedes de Dumio o la de Iria. También destaca por su vinculación al mundo monástico y con sus corrientes renovadoras, participando en el establecimiento y dotación de varias casas hasta que decide fundar el monasterio de Celanova ${ }^{2}$. En su papel de reformador de la vida monástica gallega el modelo que se pondrá a prueba en Celanova fue el resultado de una combinación de la tradición monacal visigótica y "los modelos triunfales en el mundo postcarolingio, en donde la regla benedictina ocupaba un lugar prioritario"3.

\footnotetext{
${ }^{2}$ Sobre este aspecto es obligado realizar un acercamiento a la bibliografía de Andrade Cernadas de cuya producción debe hacerse mención al menos títulos, como: ANDRADE CERNADAS, J.M.: $O$ Tombo de Celanova: estudio introductorio, edición e índices (ss. IX-XII), 2 vols. Consello da Cultura Galega, Santiago de Compostela, 1995; "La Vida cotidiana en un monasterio medieval" en Las religiones en la historia de Galicia, Santiago, 1996, pp. 295-305; "A igrexa na Gallaecia Altomedieval: San Rosendo e San Pedro de Mezonzo" en Galicia Románica e Gótica. Catálogo de la exposición "Galicia Terra Única". Xunta de Galicia, Santiago de Compostela, 1997, p.154-161; "Algunos apuntes sobre la "Vita Rudesindi" y los documentos del Tumbo de Celanova" en Sub luce florentis calami : homenaje a Manuel C. Díaz y Díaz, Santiago de Compostela, 2002, pp. 270-277. No debe obviarse en este pequeño apunte bibliográfico la reciente revisión realizada sobre la vida del santo a raíz del cumplimento del 1100 aniversario de su nacimiento: "San Rosendo e o monacato auriense do século X" en Rudesindus: o legado do santo, Santiago de Compostela, 2007, pp. 16-31; "A vida de San Rosendo: a súa familia e o seu medio: Galicia no reino Astur-Leonés" en Rosendo: o esplendor do século X, Santiago de Compostela, 2007; "Rosendo y Celanova: a la hora de la despedida" en Estudios Mindonienses 23 (2007) pp. 389-502

${ }^{3}$ ANDRADE CERNADAS, La vida cotidiana...", p. 299
} 
La proyección de esta singular personalidad no sólo queda definida a través de los diferentes apuntes que transmite la documentación contemporánea sino que sobre el mismo se redactó, ya en la segunda mitad del siglo XII, la Vita o Liber de vita et virtutibus sanctissimi Rudesindo Episcopi. A través de esta particular biografía queda aclarada la mayor parte de los episodios vinculados al santo y en especial los relacionados con la fundación de Celanova ${ }^{4}$.

Según la tradición, recogida en una carta de donación incluida en el Becerro de Celanova, estando Rosendo en el monasterio de Caaveiro (ca. 934) en una noche de vigilia recibió la revelación de que debía fundar un monasterio. Esta leyenda, que insiste en la voluntad divina de la misión del santo, es recogida en la Vita: "en sueños le inspiró una indicación divina que edificara un monasterio en la región de Limia en honor de San Salvador, en la villa que llaman Villar, cuyo nombre después el propio obispo hizo cambiar al tiempo de la construcción y decidió que se llamara Celanova"5. San Rosendo comenzará inmediatamente las gestiones para realizar su propósito emprendiendo la construcción de monasterio al poco tiempo ya que la consagración de su templo tendrá lugar el 25 de noviembre de 942 con la presencia del monarca Ramiro II.

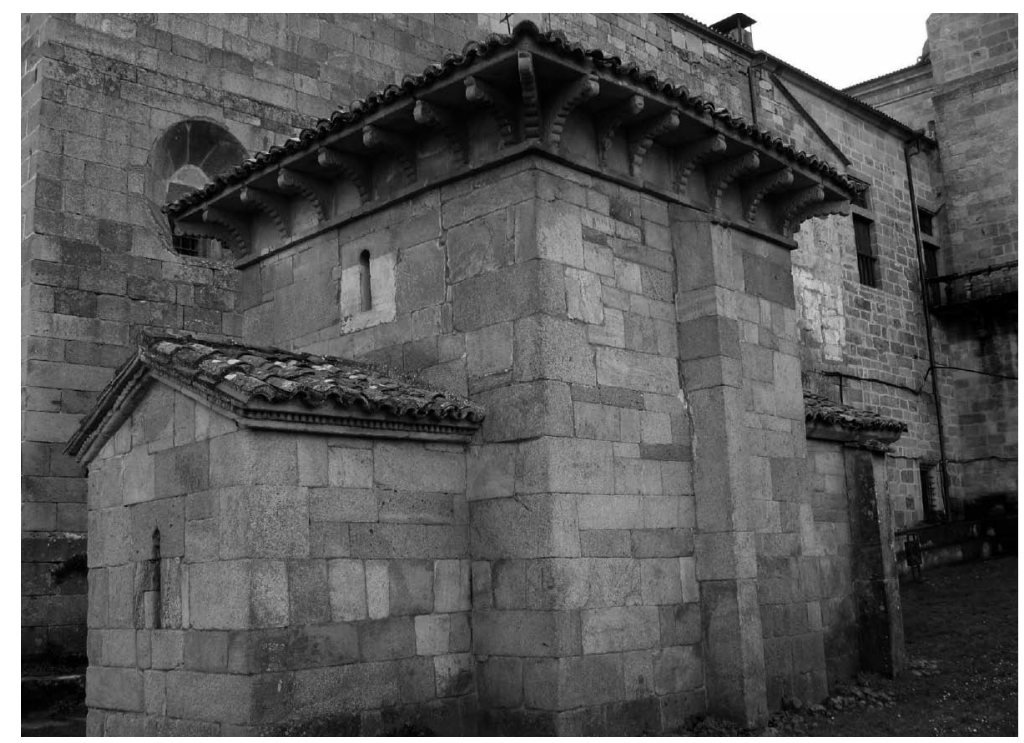

Figura 1. Vista general de San Miguel

${ }^{4}$ DÍAZ y DÍAZ, M.C. et alt.: Ordoño de Celanova: Vida y milagros de San Rosendo. Fundación Barrié, A Coruña, 1990, p. 59.

${ }^{5}$ DÍAZ Y DÍAZ, op. cit., pp. 133-135. 
Si la evaluación de la situación histórica, cultural e incluso religiosa de la Galicia del siglo $\mathrm{X}$ es complicada, no lo es menos intentar una definición del momento $\operatorname{artístico~}^{6}$.

Casi siempre se ha etiquetado el arte de este siglo bajo los calificativos de arte mozárabe o arte de repoblación, términos aplicados incluso de manera indistinta. Sin embargo, ambas expresiones no son iguales. Hoy en día se considera mozárabe, el arte vinculado a los cristianos en territorio musulmán, por lo que tan sólo puntuales ejemplos pueden considerarse como tales. Frente a esta expresión artística estaría la que podría denominarse arquitectura cristiana hispana o simplemente arquitectura del siglo $X$. Una denominación que evita el término "repoblación" al estar en revisión su aplicación como concepto histórico.

En cuanto al carácter de esta arquitectura Martínez Tejera, siguiendo a Chueca Goitia, la define como una "arquitectura de fusión": "una arquitectura profundamente hispana en su planificación pero con una estética visual emiral y califal (...) que se hace evidente en su alzado y ornamentación"7.

\section{La obra: san Miguel de Celanova}

Del pasado esplendor medieval del monasterio de Celanova tan sólo se conserva la capilla de San Miguel, declarada Monumento Nacional mediante Real Orden de 12 de abril de 1923.

En su trascendencia como Monumento la arquitectura de San Miguel se ha ido "empapando" de la tradición, la historia y la hagiografía quedando vinculada a la figura del santo fundador del monasterio, convirtiéndose en un documento, en memoria, o casi en reliquia, de San Rosendo.

Su carácter excepcional, tanto como arquitectura como también reliquia, aparece presente ya en el siglo XII. Según transmite el monje Ordoño, dentro del conjunto monástico destacaba: "el pequeño templo a San Miguel arcángel, de aspecto un pequeño refugio, construido en piedra de maravillosa labra que suscita la admi-

\footnotetext{
${ }^{6}$ Véase: YZQUIERDO PERRÍN, R.: "Arte Medieval I" en Galicia Arte. Tomo X. Hércules Ediciones, A Coruña, 1993; CARRILLO LISTA, Ma P. y FERRÍN GONZÁLEZ, R.: "Mozárabes e repoboadores. Ollada á arte galega do século X" en Galicia Románica e Gótica. Catálogo de la exposición "Galicia Terra Única". Xunta de Galicia, Santiago de Compostela, 1997, p.162-171; BARRAL RIVADULLA, Ma D.: "A arte no século X" en Historia da arte galega, tomo II. Arte Medieval, A Nosa Terra., Vigo, 2002, pp. 33- 48; VAZQUEZ CASTRO, J.: "Arquitectura en Galicia en la Alta Edad Media" en Arte e cultura de Galicia e o norte de Portugal: Arquitectura, vol.1, Nova Galicia, Vigo, 2006, pp. 49-66.

${ }^{7}$ MARTINEZ TEJERA, A.M.: El templo del Monasterium de San Miguel de Escalada: "arquitectura de fusión” en el reino de León (siglos X-XI). AEDATME, Madrid, 2005, pp. 15-16.
} 
ración de cuantos lo contemplan". Esta arquitectura quedaba vinculada a San Rosendo al afirmar que éste "izo además (...) un oratorio a San Miguel arcángel, con visos de pequeño refugio 9 .

Esta particular filiación hace que el oratorio sea respetado incluso por la importante reforma de la fábrica monástica que tiene lugar en época barroca, momento en el que además se insiste en su carácter emblemático al aparecer representado en su nueva sillería de coro donde se identifica explícitamente con el fundador del monasterio $^{10}$.

Profundizando en esta línea en 1610 Castellá Ferrer afirmaba que san Rosendo se retiraba "en oración en un oratorio, que para esto hizo dedicado al Archangel San Miguel, que está en el jardín de la Casa de Celanoua (...) está tan nueva como el día en que se acabó de labrar, y bien parece obra, y celda suya” ${ }^{11}$. También H. Oxea

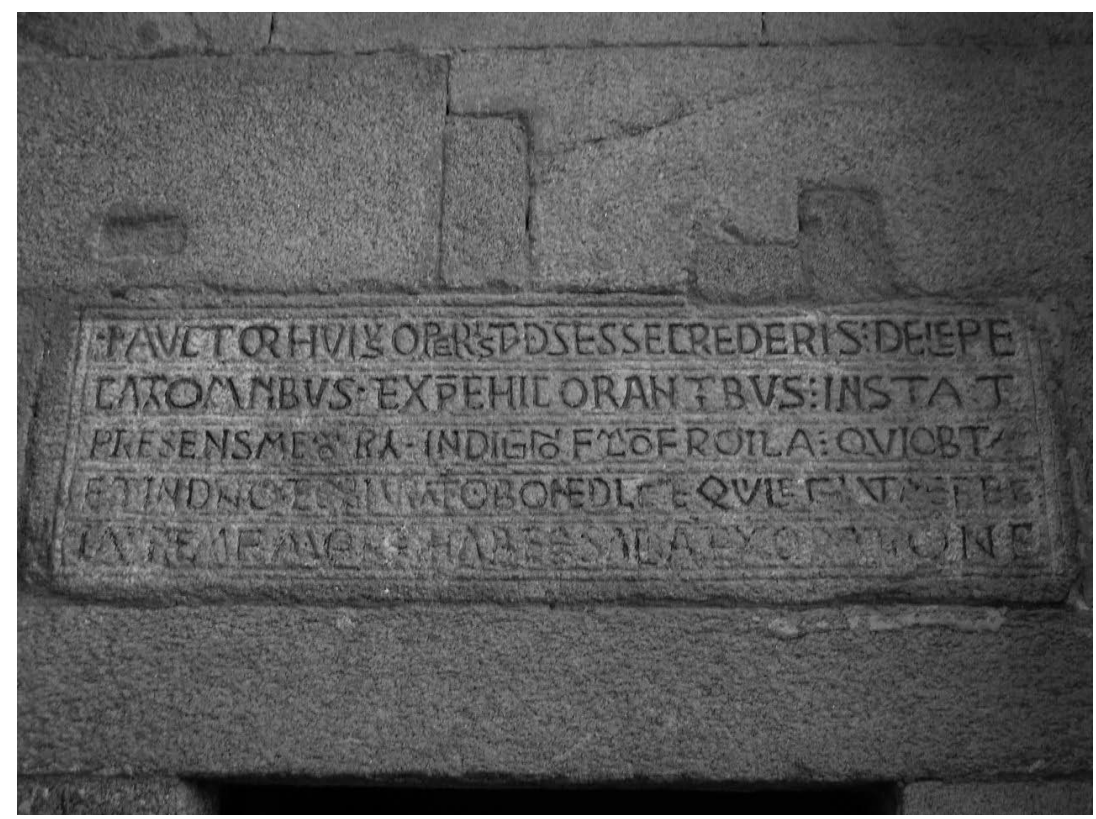

Figura 2. Epígrafe sobre la puerta de entrada

${ }^{8}$ DÍAZ y DÍAZ, op. cit., p. 143 .

${ }^{9}$ DÍAZ y DÍAZ, op. cit., p. 143

${ }^{10}$ Véase: ROSENDE VALDÉS, A.: La sillería de coro barroca de San Salvador de Celanova, Universidad de Santiago, Santiago de Compostela, 1986, pp. 53-54.

${ }^{11}$ CASTELlÁ FERRER, M.: Historia del Apóstol de Iesus Christo Sanctiago Zebedeo Patrón y Capitan General de las Españas, Ed. Facsímil de la de 1610, Xunta de Galicia, Santiago de Compostela, 2000, fol. $165 \mathrm{v}$. 
cinco años después escribía que san Rosendo "edificó en medio de la huerta, o jardín del monasterio, vn oratorio en forma de yglesia, de treinta pies de largo, quinze de ancho, con su capilla mayor y cruzero, de obra muy curiosa aunque llana, con la advocación del glorioso Arcangel san Miguel su gran devoto, y abogado, en que dixesse Missa, y pudiesse orar a solas, sin ser molestado, ni molestar a nadie"12.

Esta identificación de San Miguel con la figura del fundador ha condicionado incluso la interpretación del edificio. Sin embargo, este hilo conductor se ve trastocado tras la lectura e interpretación que del epígrafe, localizado sobre la puerta de acceso al inmueble, propuso el filólogo M. C. Díaz y Díaz.

"+AUCTOR HUIUS OPERIS TU DEUS ESSE CREDERIS:

DELE PECCATA OMNIBUS TE CHRISTE HIC ORANTIBUS

INSTAT PRESENS MEMORIA INDIGNO FAMULO FROILA:

QUI OPTAT ET IN DOMINO TE CONIURAT,

O BONE DILECTE QUI LEGIS,

UT MEI PECCATORE MEMORIA HABEAS SACRA EX ORATIONE'13

"Tú, oh Dios, autor de esta obra eres creído.

Tu, oh Cristo, borra los pecados a los que aquí oran.

La presente memoria recomienda a Froila, tu indigno siervo, el cual desea y en el Señor te conjura, oh bien amado que lees esto, para que hagas memoria de mi, pecador, en la oración sagrada".

Para Díaz y Díaz la inscripción atribuye sin duda la responsabilidad de la construcción de la capilla a Froila y no a San Rosendo. Tal interpretación se basa "en la presencia de la palabra "memoria", que aquí no puede tener significado funerario, como prueba la expresión personal "indigno famulo Froila", que no pudo escribir más que el interesado"14. Esta afirmación creo que es incontestable desde la valoración filológica del epígrafe, un dato apenas destacado por aquellos que con posterioridad al trabajo de este autor han abordado el inmueble y que remarca y condiciona sin lugar a dudas su particular idiosincrasia ${ }^{15}$.

12 OXEA, H. Fr.: Historia del Glorioso Apostol Santiago Patron de España: de su venida a ella, y de las grandezas de su Yglesia , y Orden Militar. Madrid, 1615 (reed. Santiago, 1993), fol. 292v.

${ }^{13}$ Lectura tomada de: DÍAZ y DÍAZ, op. cit., p. 143, nota nº 69.

14 DÍAZ y DÍAZ, op. cit., p. 143.

${ }^{15}$ Así se recoge en BARRAL RIVADULLA, Ma D.: San Miguel de Celanova: el silencio y la elocuencia de una arquitectura singular, Grupo Francisco de Moure, Ourense, 2006 
Sobre el carácter de la capilla de San Miguel existen diversas hipótesis sin que haya unanimidad en torno a su función. El inmueble posee una ubicación característica dentro del recinto monástico, aunque a cierta distancia del mismo. Dada esta especial localización y teniendo en cuenta las disposiciones de la Regla Benedictina la capilla de San Miguel podría identificarse, según algunos autores, con el oratorio donde tras recibir "a cuantos huéspedes llegaren al monasterio (...) Lleven a los huéspedes a rezar luego que los reciban..." 16. Además, como señala Andrade, la hospitalidad es uno de los principios mas sólidamente enraizados en el mundo monástico desde sus primeras manifestaciones ${ }^{17}$. Es decir, San Miguel respondería por tanto a una disposición según la cual los monjes visitantes o transeúntes no deberían interferir en la vida del monasterio; de ahí que estuviese ubicado en la zona próxima a los dormitorios para huéspedes.

Una segunda teoría interpreta el edificio como una cella memoriae, apoyada en el epígrafe en honor a Froila ${ }^{18}$, y en la advocación de la capilla a san Miguel, cuyo carácter psicopompo no presenta dudas. Además, cabe señalar que en el contexto del siglo X la figura del Arcángel cobra, si cabe, mayor protagonismo gracias al desarrollo del oficio de difuntos -novedoso dentro de la liturgia denominada mozárabe-. De hecho, Núñez Rodríguez plantea que la erección de esta capilla debió tener lugar una vez que el monasterio entra en una fase de bonanza, concretamente hacia los años sesenta del siglo $\mathrm{X}$, una cronología que han seguido aquellos que la han abordado posteriormente.

Para este autor en este momento el monasterio se encuentra "en situación de concede-la súa atención ós monumentos memoriais" ${ }^{19}$ y considera que, una vez fallecido Froila, la comunidad le otorgará "o especial beneficio espiritual que a lexislación eclesiástica visigoda concedía ós laicos fundadores"20. A esta argumentación se unirán las teorias de Guardia, para quien los modelos arquitectónicos leoneses propuestos para interpretar la arquitectura de Celanova -Santiago de Peñalba y Palat de Rey- fueron construidos con una función funeraria ${ }^{21}$.

Ahora bien, estas hipótesis tampoco son excluyentes puesto que la finalidad de servir como oratorio no contradice el valor memorial del edificio.

16 Tomado de NÚÑEZ RODRÍGUEZ, M.: San Miguel de Celanova, Xunta de Galicia, Santiago de Compostela, 1989, p. 25.

${ }^{17}$ ANDRADE CERNADAS, "La vida cotidiana...,, p. 298.

${ }^{18}$ NOACK-HALEY, S.: "Galicia fronte ó Islam. Arte e cultura en Galicia durante o s. X" en Santiago Al-Andalus. Diálogos artísticos para un milenio. Xunta de Galicia, 1997, p. 157-180, p. 170 para nota; GUARDIA, M.: "O oratorio de San Miguel de Celanova: arquitectura e liturxia" en Rudesindus: o legado dosanto, Santiago de Compostela, 2007, pp. 131-145, p. 139 para nota.

${ }^{19}$ NÚÑEZ RODRÍGUEZ, San Miguel..., p. 25.

${ }^{20}$ NÚÑEZ RODRÍGUEZ, San Miguel..., p. 25.

${ }^{21}$ GUARDIA, "O oratorio....", p. 140 


\section{La imagen arquitectónica de San Miguel}

San Miguel de Celanova se presenta seguidora de los postulados de la arquitectura del siglo X. En general estos edificios presentan como denominador común la geometría tanto en alzados como en planimetría, dando lugar a una particular configuración espacial concebida como sucesión de unidades espaciales calculadas, cerradas y aisladas entre sí. Se mantiene así una tendencia a la ruptura con la tradicional continuidad de espacios que ya se experimentara en la arquitectura hispanovisigoda y que surge como fruto de una liturgia que condiciona el desarrollo espacial interno al precisar de toda una serie de cámaras anexas al cuerpo principal del templo. Como en el caso hispanovisigodo lo primero que se observa en estos interiores es la gran fragmentación, no se posee nunca una visión completa del espacio, hay que recorrer el edificio para poder comprender las distintas unidades que lo componen. Esta compleja compartimentación, que huye de un espacio claro y abarcable, busca la creación de diversos ambientes, no sólo en planta sino también en alzado ya que se juega con espacios a diferentes alturas.

Desaparecen, por tanto, los espacios continuos a favor de la creación de breves espacios ópticos de límites horizontales imprecisos. La limitación de estos ámbitos se logra, casi siempre, empleando medios arquitectónicos como la creación de espacios con carácter vertical (como el cimborrio cuyo verticalismo se acentúa con una fuerte iluminación), los arcos ultrasemicirculares con forma de herradura (que acotan los espacios), las bóvedas con la misma directriz (ofreciendo la impresión de espacio laberíntico y cueviforme) o las columnas (que actúan como cortinajes para romper la fuga o huida de espacios excesivamente grandes).

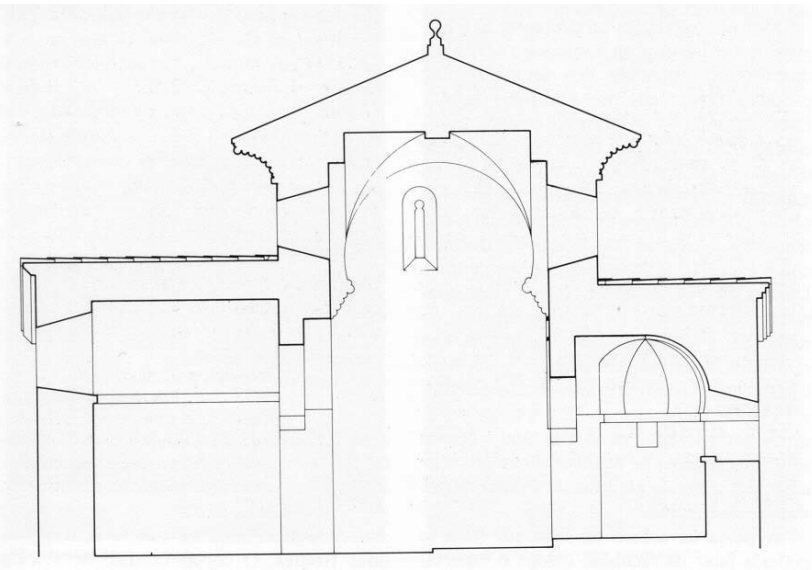

Figura 3. Planta de San Miguel de Celanova sg. Núñez Rodríguez 
Para la mayor parte de los autores que se han acercado al monumento, San Miguel constituye una esquematización de la iglesia de Santiago de Peñalba en cuya planimetría se habrían suprimido las capillas laterales y el contraábside. El resultado en planta da lugar a una particular combinación de esquemas geométricos que componen tres espacios diferenciados: uno rectangular-que cumple la función de nave-, una estructura cuadrada -que sobresale de la nave a modo de cimborrio-, y por último el ábside -de planta en forma de herradura al interior mientras que al exterior es cuadrada-.

El acceso al inmueble se realiza por el lado sur, entrada lateralizada típica de la arquitectura del siglo X y que provoca un "efecto sorpresa"; puesto que se precisa un giro de noventa grados para poder percibir la totalidad del espacio arquitectónico. El primer ámbito, a modo de nave, se presenta como un recinto de pequeñas dimensiones y cerrado por un abovedamiento de cañón cuya directriz tiende a la herradura y que arranca de una sencilla imposta.

Este espacio se separa del siguiente mediante un arco de herradura que se dobla hacia el cuerpo central. Al igual que el arco que separa el ábside del espacio central, éste está constituido mediante dovelas, realizadas en granito, con despiece radial. Un sistema de separación-organización espacial interna que remite a la arquitectura de época califal ${ }^{22}$.

El cuerpo central, de sección cuadrada, constituye el eje arquitectónico vertical del oratorio - enfatizado además por la luz-. Se cubre mediante una "bóveda de aristas", que recuerda a la que cierra el cuerpo central de Santa Comba de Bande por la distribución de los fingidos sillares en espina de pez que apean en arcos formeros los cuales, a su vez, descansan en modillones de rollos. Este recurso a la arquitectura simulada puede relacionarse con diferentes referentes pero también cuenta con paralelos en la arquitectura omeya. Esta relación con lo islámico -y concretamente con Córdoba- se refuerza al valorar las ménsulas de este cuerpo central, las cuales remiten directamente al modelo cordobés copiando los "modillones de las arcadas de la nave central de la gran mezquita"23.

${ }^{22}$ Sabine Noack afirma que: "la separación del interior de la capilla en tres espacios es subrayado por la estrechez de los pasos; sus arcos de herradura, compuestos de dovelas cuidadosamente cortadas, nacen de impostas empotradas en los muros. Manifiestan la particularidad de que su intradós y extradós no se desarrollan paralelamente, sino que la altura de las dovelas crece hacia el cenit- una evidente influencia califal, posterior en fecha a la construcción de las iglesias mozárabes del valle del Duero, ya que un arco de este tipo aparece "como uno de los primeros ejemplos en la arquitectura califal" (según K. Brisch) en un nicho del Salón Rico de Madinat al- Zahra (953- 957 d.C.). La resultante de la orientación cronológica concuerda con la datación de la capilla, sugerido por M. Núñez, en los años sesenta del siglo X”. NOACK -HALEY, op. cit., p. 173.

${ }^{23}$ NOACK -HALEY, op. cit., p. 173. 


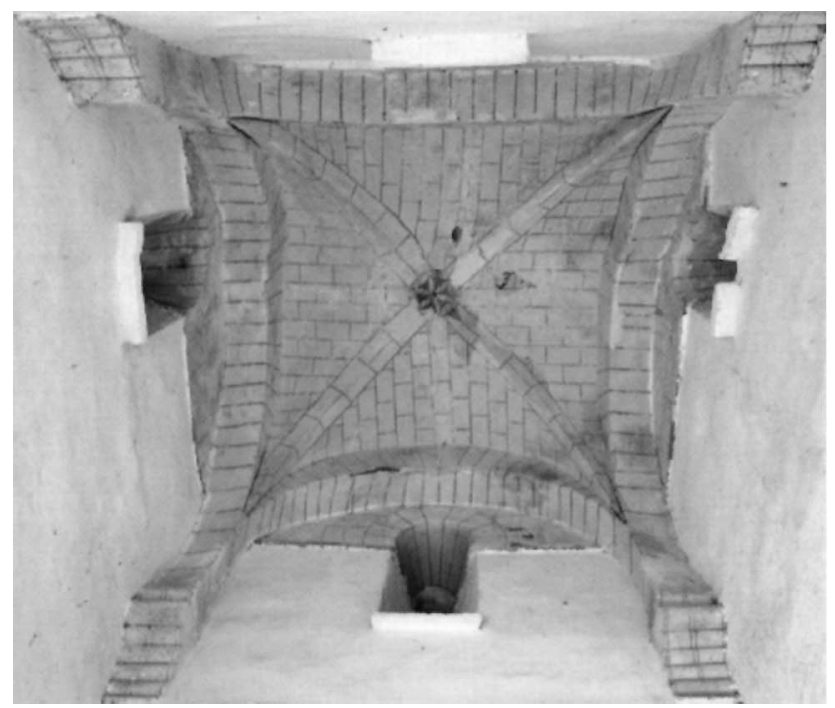

Figura 4. Vista del arranque y bóveda central

Independientemente de su origen, lo cierto es que esta solución arquitectónica permite dotar de mayor monumentalidad a este espacio. Además, al hacer que el empuje de la bóveda cargue sobre las esquinas de los muros estos quedan aligerados permitiendo abrir en la zona superior de los mismos sendos vanos de reducido tamaño, con perfil de herradura y derrame interior. Estas oquedades afianzan el principio de luz directa en cada uno de los cuerpos contribuyendo a potenciar en este caso también el efecto de altura.

El acceso al ábside se realiza a través de un arco de herradura muy peraltado enmarcado por un alfiz. Dicho arco está constituido por grandes dovelas dispuestas en despiece radial y asentadas a hueso. El hecho, como se ha mencionado, de que el intradós y el extradós no sean paralelos es lo que lo acerca a la arquitectura omeya y lo aleja del arco de herradura hispanovisigodo. No en vano muchos autores lo han parangonado con el mihrab de la mezquita de Córdoba. Sin embargo, no debe olvidarse que este mihrab data de época de Al-Hakam II (ca.962-965) y es, por tanto, posterior a la erección del edificio orensano. Siendo así más que probable que su modelo fuese el mihrab precedente -en relación con la ampliación de Abd-al-Rahman II (832-852)- o, quizás eliminar aquel que se podía contemplar en la mezquita de la ciudad residencial y administrativa de Madinat al-Zahra, dedicada en el 941, que presentaba también doble quibla.

El ábside se cubre con una pseudo-cúpula de cascos cóncavos que arrancan directamente desde el muro presentando sección de herradura. Este abovedamien- 
to remite al sistema empleado en iglesias como Santiago de Peñalba o San Miguel de Escalada y por extensión a los modelos cordobeses referenciados. Esta boveda de pseudo-gallones fue realizada en ladrillo y yeso, un guiño más a la arquitectura simulada, recurso habitual en el mundo omeya pero también presente en la realidad artística asturiana, como es el caso de los "falsos" sillares de la cabecera de San Julián de los $\operatorname{Prados}^{24}$.

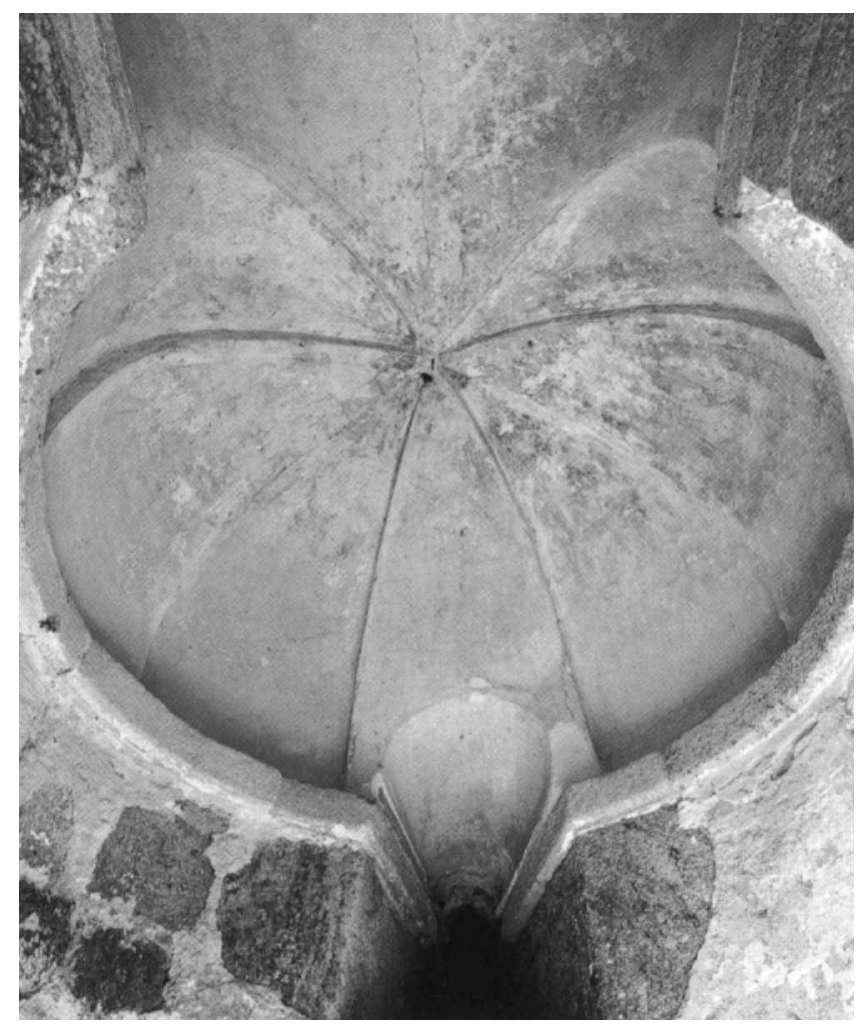

Figura 5. Vista de la bóveda de cascos del ábside

La relación con lo islámico de este ámbito, e incluso del cuerpo central, también quedaría también corroborada a nivel estético. Como afirma Grube: "la mejor y más "islámica" arquitectura islámica es realmente una negación de la arquitectura tal como se la entiende en Europa, es decir, una negación de la estructura; aspira a la negación óptica de la realidad de la carga y de la necesidad del soporte. Los dis-

${ }^{24}$ NOACK -HALEY, op. cit., p. 171. 
tintos medios con los que se crea la ilusión de la inexistencia de la carga, la ilusión del espacio ilimitado, de la inmaterialidad de los muros, pilares y bóvedas, son todos bien conocidos. Incluyen desde el uso del mosaico y la decoración pintada hasta el azulejo -en especial los vidriados y policromados- y desde la piedra o el yeso, moldurados y profundamente tallados, hasta bóvedas e incluso pilares de soporte calados y horadados"25.

El lugar más sagrado del edificio presenta el aspecto de un nicho excavado en roca puesto que aparece conformado por espesos muros. Evocando en cierto modo esa arquitectura de cavidades característica del altomedievo peninsular y vinculada también al mundo monástico. Sin embargo, en San Miguel el espacio evoluciona ante la apertura de un vano en el fondo, elemento que remite a los principios de la arquitectura de volúmenes.

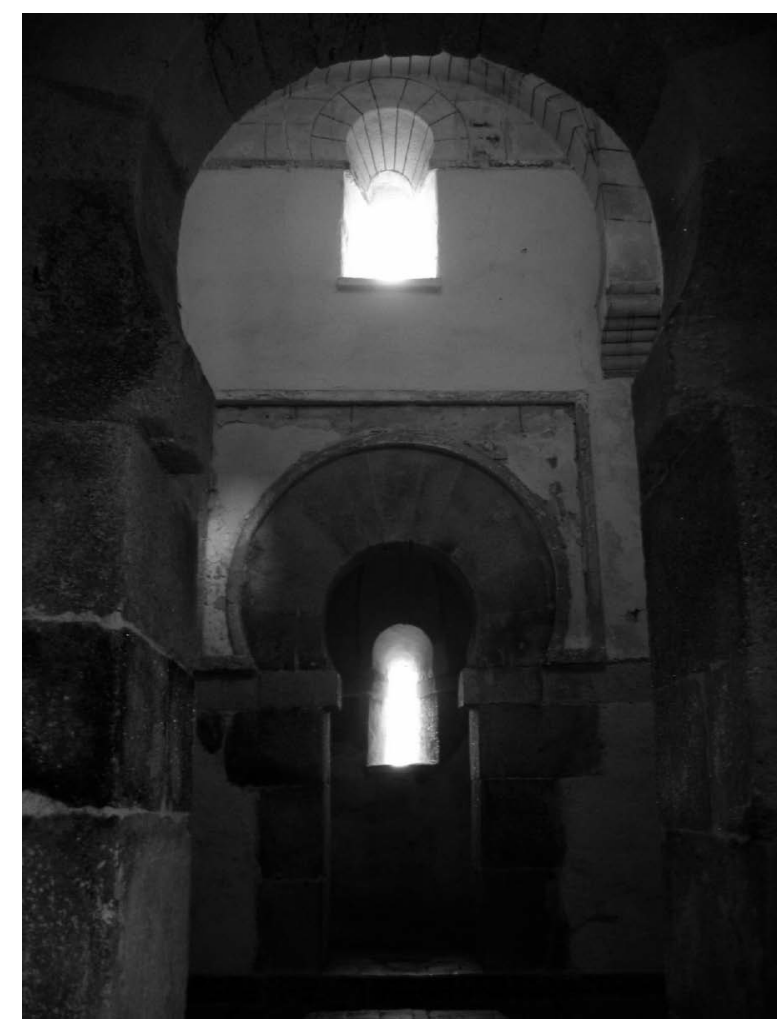

Figura 6. Pared de entrada ábside

${ }^{25}$ GRUBE, E.J.: "Introducción” en La arquitectura del mundo islámico. Alianza, Madrid, 1985, pp. 10-14, p. 10-11 para nota. 
Como conclusión puede afirmarse que el interior del oratorio de San Miguel se formula a partir de espacios aditivos. Son volúmenes cuánticos, concatenados e independientes, que se aíslan entre sí por un concepto diferente de su planimetría, de su altura, de su cubierta, y en la luz que, a niveles distintos, lo ilumina. En este interior se localizan dos ejes o direcciones, uno vertical y otro horizontal, el primero nos lleva hacia el ábside (centro litúrgico) y el segundo hacia el cuerpo central de la construcción (centro arquitectónico).

Frente a la complejidad espacial interna, el exterior de San Miguel presenta una lectura más factible, destacando sobre todo su ritmo escalonado, desapareciendo la tendencia longitudinal, y poniendo en valor las perspectivas breves. En este exterior cobra importancia el tratamiento de los paramentos que transmiten solidez gracias a la utilización de grandes sillares y de contrafuertes. Por otro lado, la ausencia de fachada, característica de la arquitectura del siglo $\mathrm{X}$, permite la percepción exterior del templo como un todo -a diferencia de lo que ocurre en el interior-.

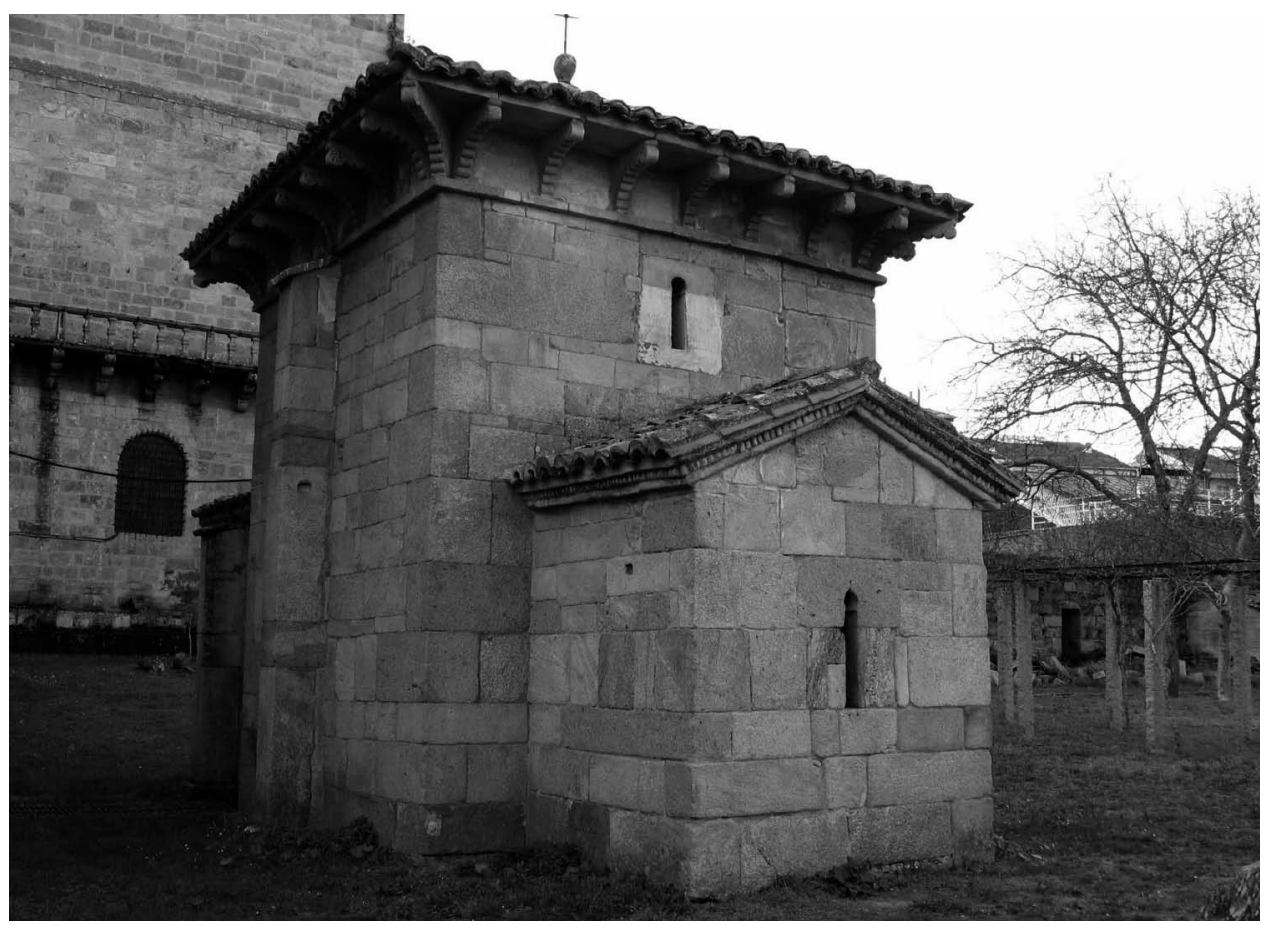

Figura 7. Exterior desde el ábside (alzado este) 
A nivel decorativo destacan dos elementos: el tratamiento de la cornisa del ábside y los modillones. Bajo el alero del ábside se presenta una cornisa exornada con dientes de sierra, motivo que se utiliza en otros ejemplos de la arquitectura del siglo $\mathrm{X}$ como Santa María de Mixós y cuyo empleo remite a la tradición artística peninsular. Los modillones, que aparecen situados bajo el alero del cuerpo central, están constituidos mediante ocho lóbulos, dispuestos en orden creciente, cóncavos, y presentan sus caras laterales labradas a bisel exornadas alternativamente con rosetas y ruedas helicoidales. Estas molduras han sido vinculadas habitualmente con la tradición cordobesa, sin embargo S. Noack destaca que frente a los modillones empleados en el interior del edificio estas molduras externas no presentan relación directa con lo cordobés sino con modelos utilizados en "iglesias como Escalada, Mazote o Peñalba. En la capilla de San Miguel, sujetan los aleros de piedra y están colocados entre campos cuadrados que se parecen a metopas, consistentes en mampostería enfoscada con apariencia de sillar. La estructura de la zona del alero a su vez, ya había sido utilizada en el ábside mayor de Escalada-aunque allí utilizando bloque de piedra para las "metopas-"26.

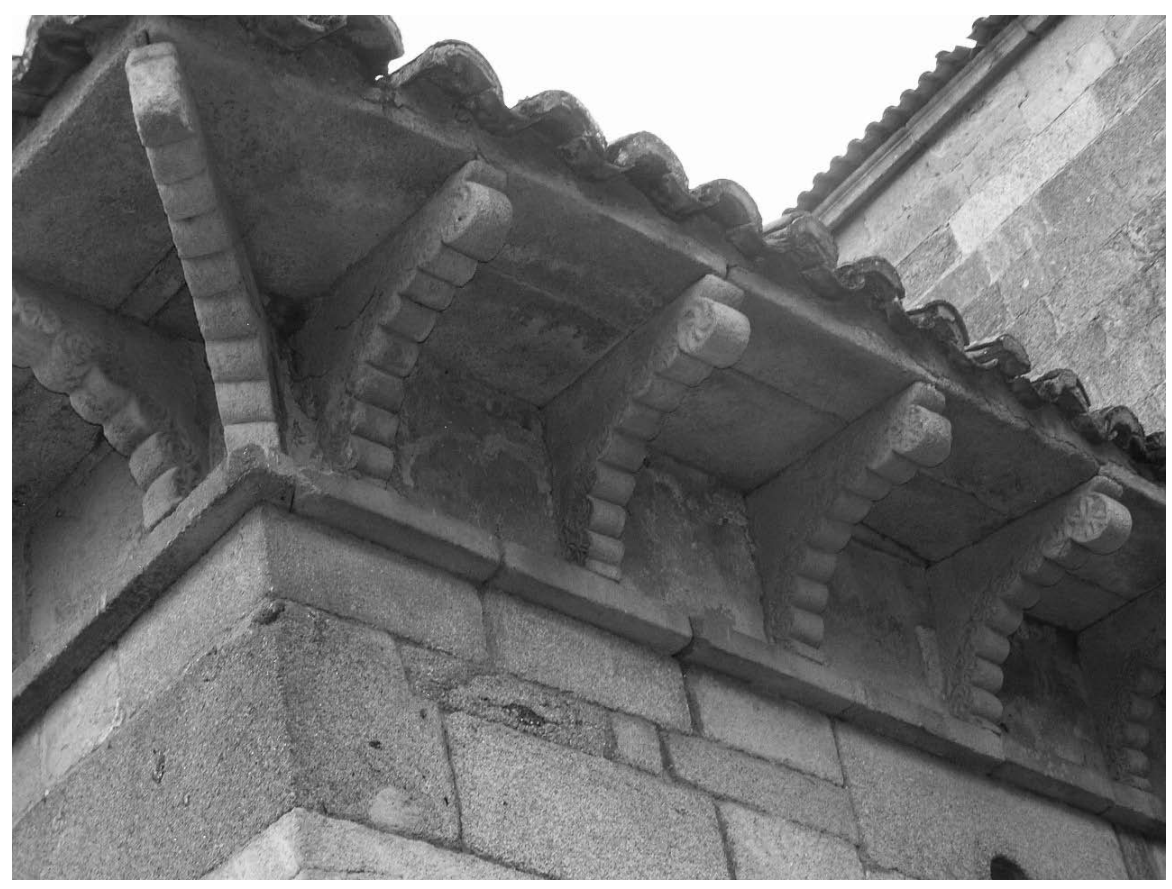

Figura 8. Detalle de los modillones de rollos del alero del crucero

${ }^{26}$ NOACK -HALEY, op. cit., p. 173 
San Miguel de Celanova constituye un ejemplo único para demostrar la "cohabitación" de distintos códigos estéticos dentro de la arquitectura del siglo X. Esta miscelánea de influencias lleva a valorar su arquitectura como una obra ecléctica, como un edificio que no "inventa un código, senón que o manexa dun modo reflexivo" 27.

Tradicionalmente, la aparición de lo islámico en el oratorio de San Miguel se ha justificado a través de la presencia de siervos de este origen geográfico trabajando en el monasterio. A este respecto se han de puntualizar algunas cuestiones: en primer lugar es necesario señalar cómo los artífices de la arquitectura del siglo X "vinculada a lo islámico" no responden a un origen cultural estrictamente mozárabe puesto que la meseta norte era una zona de menor presencia e influencia musulmana y de mayor peso de la tradición hispanogoda. Por otro lado, debe recordarse que la "repoblación" se llevó a cabo no sólo con mozárabes sino también con cristianos viejos del norte. Es decir, las fronteras geográficas del arte mozárabe no coinciden con las fronteras del fenómeno mozárabe. Como consecuencia, el "arabismo" del arte del siglo X no parece llegar por vía directa sino a través de intermediarios. En el caso gallego Núñez también recuerda que "varios foron os condes galegos que daquela se desprazaban coas súas embaixadas cara á capital califal, Córdoba, e, sen dúbida, alí entrarían en contacto coas ideas e métodos daquelas experiencias arquitectónicas" 28.

En el caso de San Miguel de Celanova habría que tener además en cuenta otros factores. Así, queda demostrado a través de la lectura del Tumbo de Celanova que san Rosendo y su familia sentían especial predilección por esta cultura, y así, poseían y admiraban las piezas artesanales islámicas. Una muestra de la presencia de este tipo de industria en Galicia pueden constituirlo las piezas de un juego de ajedrez fatimí, datado en torno al siglo $\mathrm{X}^{29}$, custodiado en el Museo de la catedral de Ourense y que forma parte del denominado Tesoro de San Rosendo.

${ }^{27}$ Núñez Rodríguez, San Miguel..., p.23

${ }^{28}$ Núñez Rodríguez, San Miguel..., p.23

${ }^{29}$ Aunque en su momento varios autores propusieron una cronología posterior, en fechas más recientes Carrero vuelve a defender la tradicional adscripción cronológica al siglo X por los paralelos que se pueden establecer con los otros dos juegos de ajedrez conservados vinculados con San Millán de la Cogolla y con San Genadio. CARRERO SANTAMARÍA. E.: "Piezas de Ajedrez del Tesoro de San Rosendo" en Encrucijadas. Las Edades del Hombre, Catedral de Astorga, Astorga 2000, pp. 238239; Idem: "Piezas de Ajedrez del Tesoro de San Rosendo" en Olor de santidade. Relicarios de Galicia, Santiago de Compostela, 2004, pp. 275-276; VALDES FERNÁNDEZ, F.: Las figuras de ajedrez y cristal de roca del museo catedralicio de Orense, Ourense, 2004. Este último autor amplía la cronología de las piezas para datarlas entre mediados de siglo IX y segunda mitad del siglo XI. Op. cit., p. 36 . 
Recientemente, C. Barros, destacó otro aspecto de la vinculación personal de la familia de san Rosendo con los musulmanes; y es el hecho de que una de sus cuñadas, la esposa de Froila, se llamase Sarracina haciendo hincapié en que ambos habían realizado la donación del lugar sobre el que había de erigir la abadía. Según este autor "sarraceno/a como antropónimo serve, ou serviu, de honra e recordatorio na Galicia nobiliaria dos séculos X e XII as vitorias militares contra o Islam, amais de indicar en xeral unha identidá musulmán, pasado e/ou presente, de tipo polo regular servil e popular" 30 . Concluye que "a falta de documentación sobre presenza mozárabe en Celanova e si dun significativo número de musulmáns, máis ou menos convertidos (...) levanos a considerar de xeito máis genuino unha participación directa mudéxar, co patrocinio de Fruela e a sú Muller Sarracina, na construcción primeira da abadía de Celanova"31.

Una vez expresado este reconocimiento de san Rosendo hacia la cultura islámica ¿por qué no hacer extensible esta admiración a sus arquitecturas? El interrogante planteado puede argumentarse además si, como parece demostrado, san Rosendo intervino personalmente en el acondicionamiento de su monasterio. Este hecho se deduce de las palabras recogidas en el Tumbo de Celanova a través de las que san Rosendo afirmaba: "relinquo vobis domum mirifice aedificatam" (os dejo una casa maravillosamente construida) ${ }^{32}$.

Esta admiración por lo islámico es lo que S. Moralejo definió como el "encanto de enemigo"33 y que se corresponde en el campo de la historia del arte con el impacto de la arquitectura califal en el arte cristiano peninsular ${ }^{34}$. Idea en consonancia con un arte que traspasa estéticamente las fronteras de dos mundos opuestos.

Es evidente que San Miguel de Celanova se distancia del mundo hispanovisigodo, sobre todo en su concepción del sanctuarium altaris ya que éste queda -al ser cueviforme- convertido en un espacio mínimo, en el que apenas hay lugar para el oficiante. La importancia de este lugar aparece remarcada también por la pre-

${ }^{30}$ BARROS, C.: “A Celanova das tres culturas, séculos X-XI” en Rudesindus: o legado do santo, Santiago de Compostela, 2007, pp. 88-101, concretamente véanse las pp. 95- 101, p. 98 para nota.

31 BARROS, op. cit., p. 101.

32 Tomado de NÚÑEZ RODRÍGUEZ, San Miguel..., p. 14.

${ }^{33}$ Definido este término en el marco de unas conferencias celebradas con ocasión de la exposición Santiago Al-Andalus. Diálogos artísticos para un milenio. Esta conferencia no llego a ser publicada. Sobre este aspecto puede consultarse también MAKARIOU, S.: "Traslado, recepción y fascinación: los objetos islámicos en Europa en torno al siglo X" en Rudesindus. La Cultura europea del siglo X, Santiago de Compostela, 2007, pp. 182- 192.

${ }^{34}$ GUARDIA, M.: "Galicia e León nos séculos IX e X. Arte de repoblación no Noroeste e na fronteira” en San Froilán. Culto e Festa, Xunta , Santiago, 2006, pp. 106-135, p. 11 para nota. 
sencia de un arco de herradura y alfiz ${ }^{35}$ que remiten a la iconografía arquitectónica del Islam ${ }^{36}$.

Quizás en este caso, como en el de la sala de oración cordobesa, haya que realizar una lectura de esta organización arquitectónica y espacial de manera más profunda. Como se decía en líneas anteriores, una valoración en consonancia con el significado de la arquitectura islámica y en relación con el propio concepto y finalidad del edificio orensano, una capilla memorial en la que el ábside, como en el caso del mihrab en la mezquita, no debe albergar la realización de un ritual litúrgico sino que únicamente constituye un referente para la oración, marcando además el punto por donde ha de llegar, tras la muerte, la Gloria.

Por otro lado la formulación del interior del oratorio parece adscribirse a aquellas afirmaciones que Chueca Goitia realiza en su clásico Invariantes castizos en la arquitectura española. Para este autor: "Se ha venido a decir que en la arquitectura musulmana no existe el sentimiento de espacio, y esto es absolutamente falso. Lo que sucede es que el espacio occidental es continuo, perspectivista y, por consiguiente, fugado (...) en cambio el espacio, digamos árabe, es de índole totalmente distinta (...) podríamos llamarlo espacio cuántico formado por emanación de cuantos espaciales (...) desconoce la fuga y parece que a veces voluntariamente la proscribe valiéndose de muchos recursos: ofuscación de la vista o ruptura por pantallas arquitectónicas de la fluencia del rayo visual" 37.

Así pues, en San Miguel de Celanova lo islámico está presente en lo epitelial, en los elementos estéticos y en la concepción espacial. Pero también, singularmente, este oratorio se adscribe, al menos parcialmente, a uno de los postulados fundamentales de la arquitectura islámica, la arquitectura oculta, que queda patente en su exterior matérico mientras que en su interior destacan los valores espaciales y lumínicos. A este respecto E. J. Grube afirma "uno de los rasgos más llamativos de todos los monumentos arquitectónicos islámicos es su interés prioritario en el espacio cerrado, en el interior como contraposición al exterior de la fachada o a la articulación general exterior de un edificio (...) en todas las épocas y en todas las regiones del mundo podemos encontrar "arquitectura oculta", es decir, una arquitectura que realmente existe, no cuando se ve como un monumento o símbolo visible para

\footnotetext{
${ }^{35}$ Sin embargo, la utilización del alfiz cuenta con precedentes peninsulares como San Salvador de Valdediós o San Miguel de la Escalada, en ambos casos y en el de Celanova el alfiz presenta diferencias con el cordobés, puesto que en este último las líneas son tangenciales al trasdós mientras que en Celanova están separadas.

${ }^{36}$ NOACK -HALEY, op. cit., p. 173

37 CHUECA GOITIA, F.: Invariantes castizos en la arquitectura española. Invariantes en la arquitectura hispanoamericana. Manifiesto de la Alambra, Dossat, Madrid, 1981, pp. 57-58
} 
todos y desde otras partes, sino sólo cuando se accede a ella y se obtiene la experiencia de su interior (...) la "arquitectura oculta" puede considerarse como la forma principal y predominante de la verdadera arquitectura islámica" ${ }^{38}$. Como adaptación de este principio Celanova presenta una arquitectura que realmente existe al interior aunque no tiende a ocultar todos sus rasgos a través de un exterior inexpresivo. San Miguel de Celanova "denota un proyecto homogéneo y una clara intención estilística con riqueza de detalles que convierten esta creación en manifestación del mencionado gusto de sus benefactores por el "despliegue de suntuosidad". Será significativo que el maestro de obra se haya servido precisamente de motivos derivados de la arquitectura omeya para perseguir este fin"39.

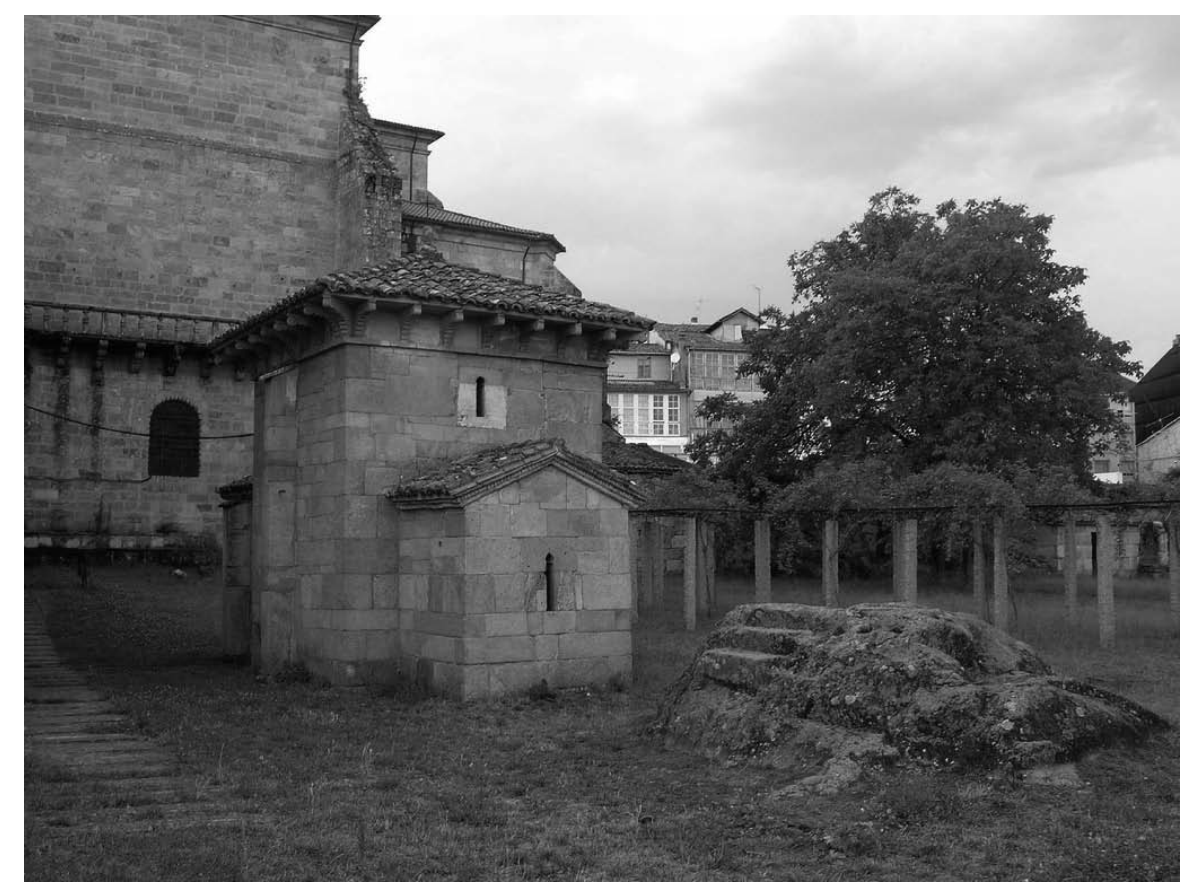

Figura 9. Vista general de San Miguel

Para cerrar esta lectura de la arquitectura de San Miguel cabe valorarla también dentro de su contexto físico. Para ello hay que destacar la interpretación que sobre el entorno del monumento propone F. Singul. Para este autor, la roca cercana al inmueble, anterior y respetada a lo largo del tiempo, permite plantear la hipótesis

\footnotetext{
${ }^{38}$ GRUBE, op. cit., p. 10 .

${ }^{39}$ NOACK -HALEY, op. cit., p. 177.
} 
de que la misma forma parte de algún ritual, probablemente procesional, en el que quedarían vinculados el oratorio y la roca. Este autor propone la lectura del conjunto como parte del ceremonial del domingo de Resurrección que en Jerusalén unía el Santo Sepulcro y el Gólgota ${ }^{40}$. Para ello se basa en que es factible pensar que Rosendo conociese dicha liturgia a partir de lecturas como la Crónica de Egeria, que el santo dona a la biblioteca del monasterio. Por otra parte, la sillería de coro barroca nos muestra un panel donde no sólo aparece representada la capilla de San Miguel junto al fundador del monasterio, sino que también acoge la imagen de la roca sobre la que aparece una cruz ${ }^{41}$. Así "coa creación da capela de San Miguel de Celanova prodúcese unha nova percepción do espacio e da naturaeza, de modo que a roca, preexistente a todo o humano é quen agora de suscitar unha resposta emocional concreta. Por virtude desta interrelación, o conxunto oratorio-roca -Sepulcro-Gólgota- e o seu contorno funerario favorecerían en Celanova a ordenación dun espazo sagrado, integrado no contexto xeral do conxunto monástico, no cal se escenificaba, con finalidade ritual, a evocación do lugar máis sagrado da cristiandade" $"$.

${ }^{40}$ SINGUL, F.: "Simboloxía do espazo. San Miguel de Celanova eo seu contorno" en Rudesindus: o legado do santo, Santiago de Compostela, 2007, pp.146-154.

${ }^{41}$ Interpretada por Rosende como un cruceiro. ROSENDE VALDÉS, op. cit., pp. 53-54.

42 SINGUL, op. cit., p. 154.

Entregado el 15.05.2009. 